\title{
MECANISMO DE RIFTEAMENTO DA PORÇÃO ORIENTAL DA MARGEM NORTE BRASILEIRA
}

\author{
JOÃO BATISTA DE LELLIS FRANÇOLIN* e PETER SZATMARI**
}

\begin{abstract}
During early Cretaceous, pre-Alagoas time (144-119 Ma), the South Atlantic rift system opened up by clockwise rotation of South America relative to Africa about a pole located at $70 \mathrm{~S}$ and $39^{\circ} \mathrm{W}$. This rotation created a unique stress field in and around the present Potiguar Basin in NE Brazil. It is characterized by E-W compression as the rotating tip of South America was pressed against the Cameroon margin in the east, and N-S extension while the continent was pulled away from the Nigerian margin in the north. This stress field reactivated the numerous Precambrian ductile. shear zones of the area by ruptile transcurrent faulting: right lateral strikeslip along the NE trending Portalegre-Carnaubais Fault and left lateral strikeslip along the E-W trending Patos fault. Imperfect fit between the laterally dislocated, rotated blocks created fault bounded half grabens. The largest one is the oil-bearing Pendência graben of the Potiguar Basin. It formed along the northeastern transtensional segment of the Portalegre-Carnaubais Fault; its southern portion displays broad folds in the early Cretaceous sequence. South of the graben, an E-W trending dike swarm, 126 millions years old, lies along the axis of greatest compression separating the transtensional and transpressional segments of the Portalegre-Carnaubais fault.
\end{abstract}

INTRODUÇÃO A margem equatorial brasileira abriga as bacias Potiguar, Ceará, Barreirinhas, Plataforma do Pará-Maranhão, Foz do Amazonas e Plataforma do Amapá. A evolução tectono-sedimentar de cada uma dessas bacias vem sendo estudada em separado por vários grupos dentro da Petrobrás, com a finalidade de prospectar hidrocarbonetos em trabalhos de detalhe e semidetalhe. No início de 1984 foi formado um grupo de trabalho, reunido no centro de pesquisas da Petrobrás (Cenpes), com a finalidade específica de realizar a integração dessas bacias.

Este trabalho, que já foi apresentado em encontros internos na Petrobrás e no IX Congresso Brasileiro de Paleontologia em setembro de 1985 em Fortaleza (Françolin \& Szatmari 1985), traz parte dos dados e das conclusões de um trabalho regional de toda a margem equatorial brasileira, o qual vem sendo publicado em partes. Esta nota se atém apenas a discussões referentes ao mecanismo de rifteamento do extremo oriental da margem norte brasileira, especificamente a oeste de Fortaleza, apesar de levar em consideração informações das outras bacias da margem equatorial. Nesta área os dados foram obtidos principalmente nas bacias Potiguar e Rio do Peixe. A primeira, por ter um grande número de dados levantados pela Petrobrás, além de seu interesse econômico para a prospecção de petróleo; e a segunda por ter, no entendimento dos autores uma evolução tectono-sedimentar intimamente ligada à da Bacia Potiguar.

Apresenta-se a seguir um resumo com a explanação dos pontos principais, seguido da estratigrafia sucinta e arcabouço estrutural das bacias Potiguar e Rio do Peixe e, finalmente, a evolução tectono-sedimentar cretácea da área em estudo.

A separação entre os continentes sul-americano e africano se deu predominantemente pelo movimento divergente de direção leste-oeste. Atualmente, o componente leste-oeste da separação é cerca de oito vezes maior que o norte-sul.
As primeiras manifestações da separação ocorreram no Jurássico Superior e já nessa época a tendência de movimentação divergente leste-oeste era clara. Tornava-se necessário, porém, para que essa movimentação se efetivasse, que o Continente Gondwana fosse partido em dois fragmentos por uma fratura de milhares de quilômetros de extensão (Fig. 1A). A fratura iniciou-se no sul do Continente Gondwana e, progressivamente, alastrou-se, durante o Cretáceo Inferior, em direção a norte (Rabinowitz \& LaBrecque 1979), moldando-se às linhas de fraqueza preexistentes no substrato (Szatmari et al. 1984).

Portanto, no início da separação, o movimento divergente a sul era maior que a norte, imprimindo uma rotação de sentido horário na placa sul-americana em relação à África (Rabinowitz \& LaBrecque 1979). O pólo dessa rotação esteve localizado, durante o Cretáceo Inferior, no Nordeste brasileiro, a sul da cidade de Fortaleza e a norte da Bacia de Tucano, aproximadamente a 390 de longitude W e 70 de latitude S, portanto a SE do ponto proposto por Rabinowitz \& LaBrecque (op. cit.). A permanência do pólo da rotação nessa região, durante todo o Neocomiano, foi condicionada pela complexidade estrutural da área, que é compartilhada pelas zonas de cisalhamento pré-cambrianas de Patos e Pernambuco, orientadas segundo a direção leste-oeste.

A rotação horária do continente ao redor do pólo localizado no ponto acima descrito causava na atual margem equatorial brasileira compressão a oeste e distensão a leste do pólo: o trecho a oeste de Fortaleza era submetido a compressão enquanto o trecho a leste era a distensão, ambas de direção norte-sul. Na margem leste, a rotação causava compressão a norte e distensão a sul do pólo: o trecho localizado a sul de João Pessoa era submetido a distensão e o trecho a norte a compressão, ambas de direção leste-oeste (Fig. 1B; Szatmari et al. 1985a, 1985b, 1987).

Dessa maneira a Província Pré-Cambriana do extremo nordeste do Brasil, denominada Província Borborema (Al-

\footnotetext{
* Petrobrás/Debar/Dinter. Rua Interventor Mário Câmara, 2783, CEP 59000, Natal, RN, Brasil

** Petrobrás/Centro de Pesquisas e Desenvolvimento Leopoldo A. Miguez de Mello (Cenpes). Cidade Universitária, Quadra 7, Ilha do Fundão, CEP 21910, Rio de Janeiro, RJ, Brasil
} 

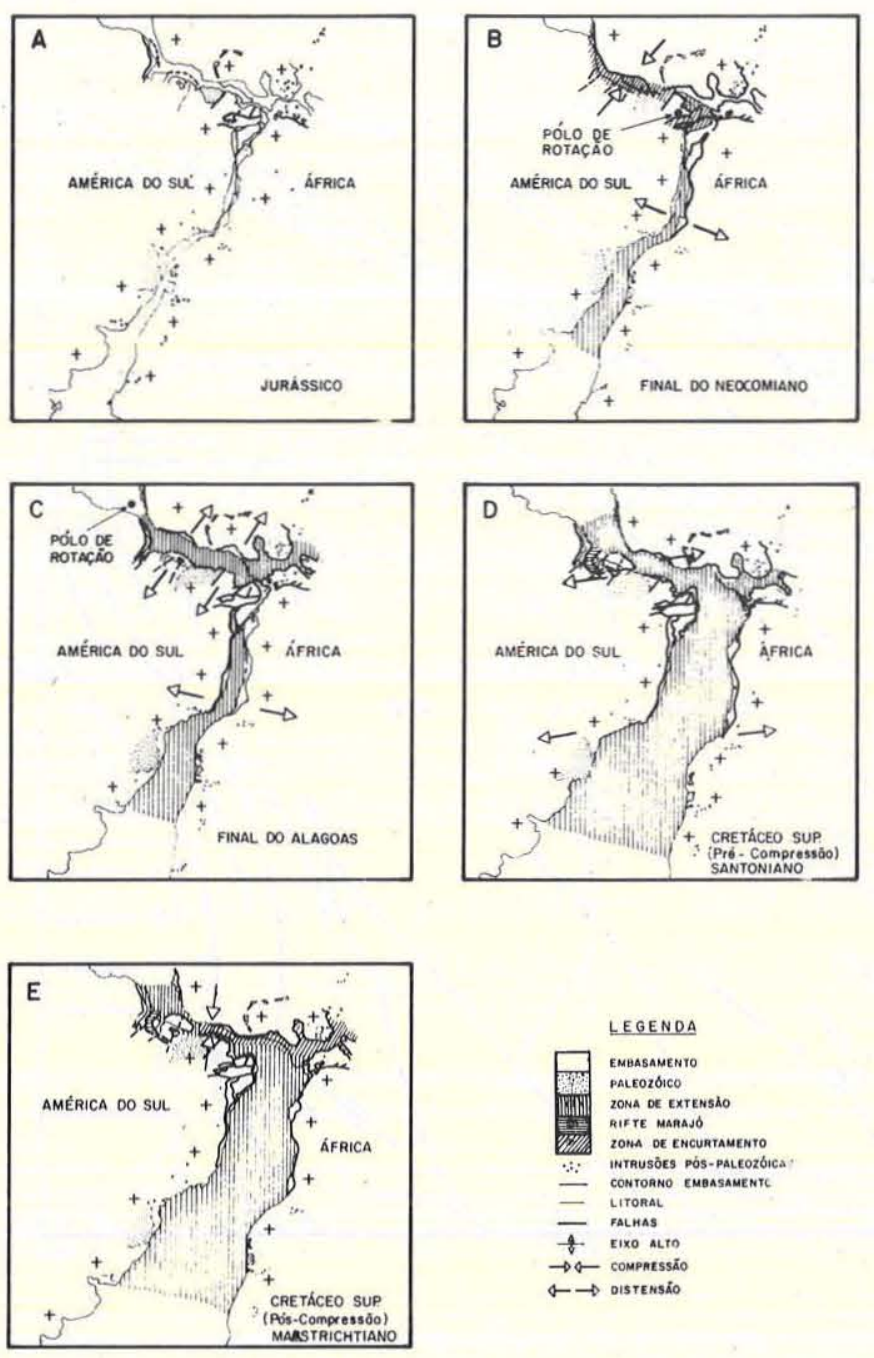

\section{LEGENDA}

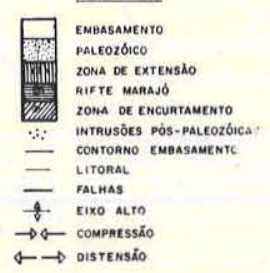

Figura 1 - Esquema da evolução da separação dos continentes sul-americano e africano. $O$ contorno dos continentes foi traçado segundo as linhas de costa atuais. No encaixe dos continentes não foi considerado o estiramento crustal das bordas continentais. Observar a mudança do pólo de rotação nos quadros B e C. Autores: Szatmari et al. $(1985 b)$

meida \& Hasui 1984) sofreu, durante o Neocomiano, uma compressão de direção leste-oeste e uma distensão norte-sul. Esse regime de esforços ocasionou a formação e a reativação de numerosas falhas na região: na área norte da Província Borborema, nas proximidades da atual linha de costa, foram formadas ou reativadas falhas normais de direção aproximadamente leste-oeste, originando os grábens da atual porção submersa da Bacia Potiguar. As numerosas falhas de direção NE-SW preexistentes foram reativadas por movimentos transcorrentes dextrais, com movimentação transtensional, (transcorrência divergente) em seu extremo $\mathrm{NE}$ (próximo à linha de costa) e transpressional (transcorrência convergente) nas porções SW (mais internas ao continente). O limite entre os regimes transpressional e transtensional é marcado por uma linha de diques básicos de direção $\mathrm{E}-\mathrm{W}$, denominada Magmatismo Rio Ceará-Mirim (Projeto Radambrasil 1981), de $126 \pm 4$ Ma (Ebert \& Brochini 1968, Sial 1976, apud Projeto Radambrasil, op. cit.) (Fig. 2). A direção NW-SE é pouco representada nessa fase com um número pequeno de falhas. $\mathrm{O}$ início da evolução tectono-sedimentar das bacias Potiguar e Rio do Peixe está intimamente ligado a esse contexto estrutural, com seus riftes neocomianos encaixados e controlados pelas direções de falhas acima descritas (Fig. 2; Szatmari et al. 1985a).

Dessas falhas, a de maior importância é a de Carnaubais-Portalegre, que propiciou a formação e delimitou o Gráben Pendência da Bacia Potiguar, além de influir decisivamente na formação da Bacia do Rio do Peixe (Fig. 2). Denomina-se aqui de Gráben Pendência a depressão morfoestrutural preenchida pela formação homônima.

$\mathrm{Na}$ Bacia Potiguar, os sedimentos dessa fase (Formação Pendência) não afloram e só podem ser observadas por poços e métodos geofísicos (gravimetria, magnetometria $\mathrm{e}$ sísmica de reflexão).

Na Bacia do Rio do Peixe, a seqüência sedimentar equivalente à Formação Pendência em idade, ambientes sedimentar e tectônico é bem exposta e pode ser estudada em vários afloramentos. Neles, o caráter transtensional dextral da Falha de Portalegre pode ser facilmente constatado pela observação de milonitos brechados, sedimentos cisalhados e estriamentos dos planos da falha, como será detalhado.

A Província Borborema permaneceu submetida ao regime de esforços acima descrito até o início do Aptiano, quando a maioria dos esforços compressivos de direção leste-oeste havia sido dissipada pela movimentação de falhas, abertura de grábens e soerguimento do cráton.

Prosseguia ainda durante o Aptiano a rotação horária do continente sul-americano em relação ao africano. Entretanto, durante esse tempo, a Província Borborema esteve submetịda apenas a uma distensão de direção norte-sul (Fig. 1c), uma vez que a compressão contra a margem oeste do continente africano (República dos Camarões) já fora dissipada na fase anterior pelos mecanismos acima descritos.

Sob esse novo regime de esforços (distensão norte-sul) interromperam-se a movimentação transcorrente dextral das falhas NE-SW e a sedimentação das bacias Rio do Peixe e Potiguar emersa. Prosseguia entretanto o rifteamento através das falhas de direção leste-oeste, com a deposição de sedimentos na parte submersa da Bacia Potiguar. É também durante essa fase que o rifte da margem equatorial se alastra para oeste, iniciando-se a sedimentação nas bacias do Ceará e Barreirinhas, e o pólo de rotação da América do Sul em relação à África migra para noroeste, em direção ao atual litoral do Amapá (Fig. 1c). Até o final do Aptiano ocorreram o rifteamento e a deposição contínua de sedimentos em toda a margem equatorial brasileira.

No início do Albiano, a crosta continental do Gondwana encontrava-se rompida ao longo de toda a atual margem continenral atlântica sul-americana, permitindo o início do movimento divergente leste-oeste entre os continentes sul-americano e africano. Tal movimentação causou, a partir do início do Albiano, um cisalhamento lateral dextral na atual margem equatorial brasileira (Fig. 1c). Também nessa fase (Albiano Inferior) iniciou-se a deposição de sedimentos no extremo norte da costa leste, entre João Pessoa (PB) e Touros (RN), permitindo a entrada do mar Albiano que causou a grande transgressão marinha em todas as bacias da margem equatorial brasileira. São então depositados os sedimentos marinhos transgressivos da Bacia Potiguar entre o Albiano e o Campaniano. Após o Campaniano, um evento 


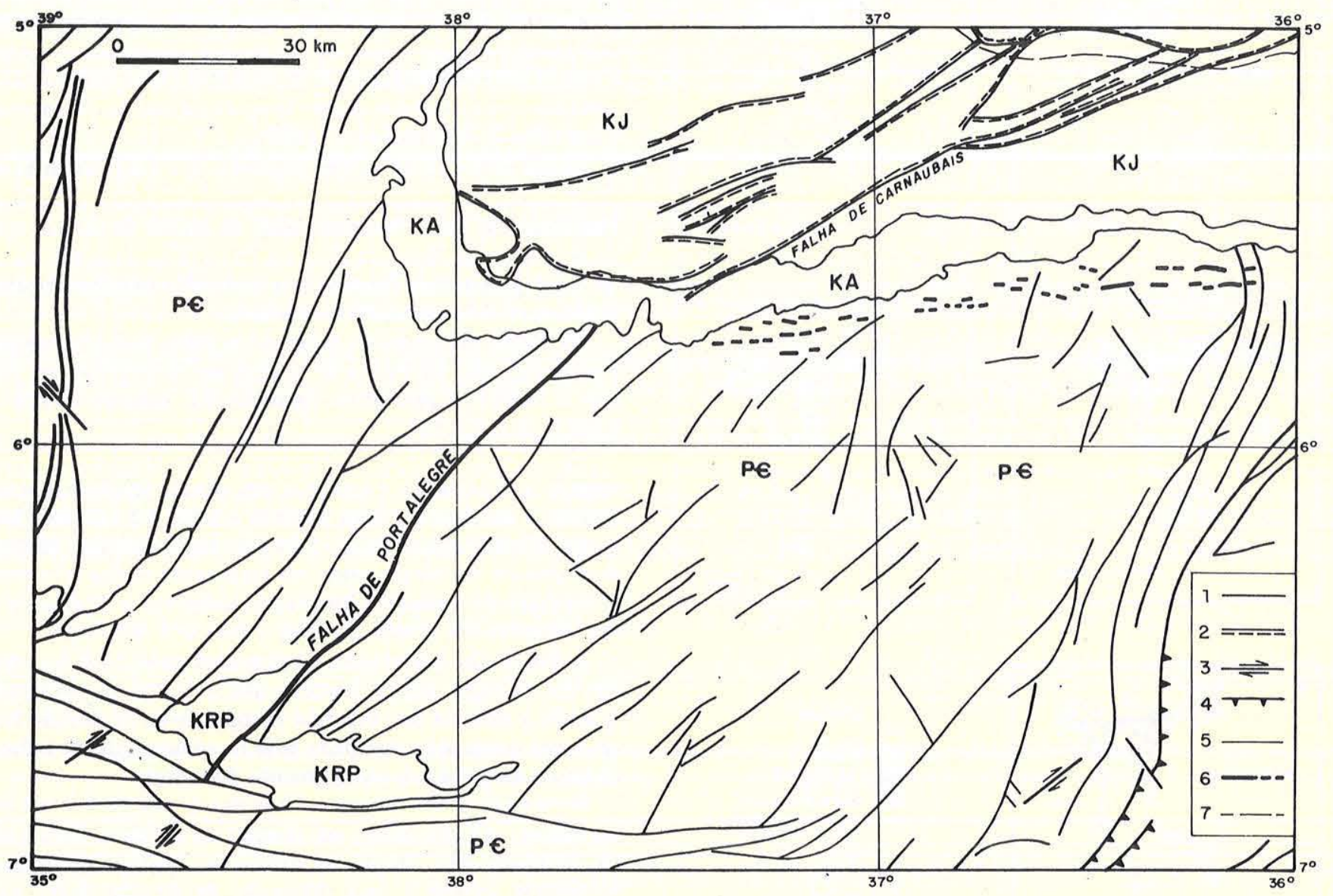

Figura 2 - Relação das bacias Potiguar e Rio do Peixe com as estruturas do embasamento circunvizinho: 1. falha mapeada por imagens de radar; 2. falha mapeada por linha sísmica; 3. falha transcorrente; 4. falha de empurrão; 5 . contato litológico; 6. diques básicos do Magmatismo Rio Ceará-Mirim; 7. linha de costa; KA. Formação Açu (Bacia Potiguar); KJ. Formação Jandaira (Bacia Potiguar); KRP. Grupo Rio do Peixe (formações Antenor Navarro, Souza e Rio Piranhas da Bacia do Rio do Peixe). Modificado de Radambrasil (1981) por Françolin \& Szatmari (1985)

compressivo de direção norte-sul se faz sentir principalmente nas áreas a oeste da Bacia Potiguar, afetando as bacias do Ceará e Barreirinhas. Tal evento não é de natureza clara e pode estar ligado ao início da Orogenia Caribeana e aos fortes dobramentos ocorridos durante o Neocretáceo no Gráben de Benuê (África). Os efeitos foram tênues na Bacia Potiguar: o soerguimento da plataforma carbonática da Formação Jandaíra e a reativação de numerosas falhas na bacia podem estar ligadas a essa compressão.

A Bacia do Rio do Peixe está preenchida por sedimentos neocomianos depositados durante a primeira fase tectono-sedimentar aqui proposta. Vários autores defendem a tese de que a sedimentação aptiana cobriu extensa faixa do nordeste brasileiro, incluindo a Bacia do Peixe, sendo essa cobertura aptiana posteriormente removida pela erosão. Não se nega aqui esta possibilidade, mas faltam estudos para confirmá-la.

BACIA POTIGUAR Estratigrafia Localizada no nordeste brasileiro, entre as cidades de Fortaleza e Natal, a Bacia Potiguar está preenchida por sedimentos depositados desde o Esocretáceo (Neocomiano) até o Recente (Regalli \&Gonzaga 1982), com interrupções representadas por discordâncias regionais (Fig. 3), que separam quatro megasseqüências:

a) Seqüência Rifte (Asmus \& Guazelli 1981) - Formação Pendência.

b) Seqüência Proto-Oceânica (Asmus \& Guazelli 1981) Formação Alagamar.

c) Seqüência Marinha Transgressiva - Formações Açu, Ponta do Mel, Ubarana Membro Quebradas e Jandaíra.

d) Seqüência Marinha Regressiva - Formações Tibaú, Guamaré e Ubarana.

A estratigrafia aqui adotada foi atualizada por Souza (1982), modificada pelo grupo de trabalho Petrobrás/ Debar/Dinter em 1984 e está sumarizada na figura 3. As relações espaciais entre as diversas formações podem ser observadas na figura 4.

Arcabouço Estrutural O arcabouço estrutural da Bacia Potiguar foi definido em sua fase rifte, durante o Neocomiano, quando se iniciou a formação dos grábens.

A bacia é formada por um gráben profundo em sua por- 


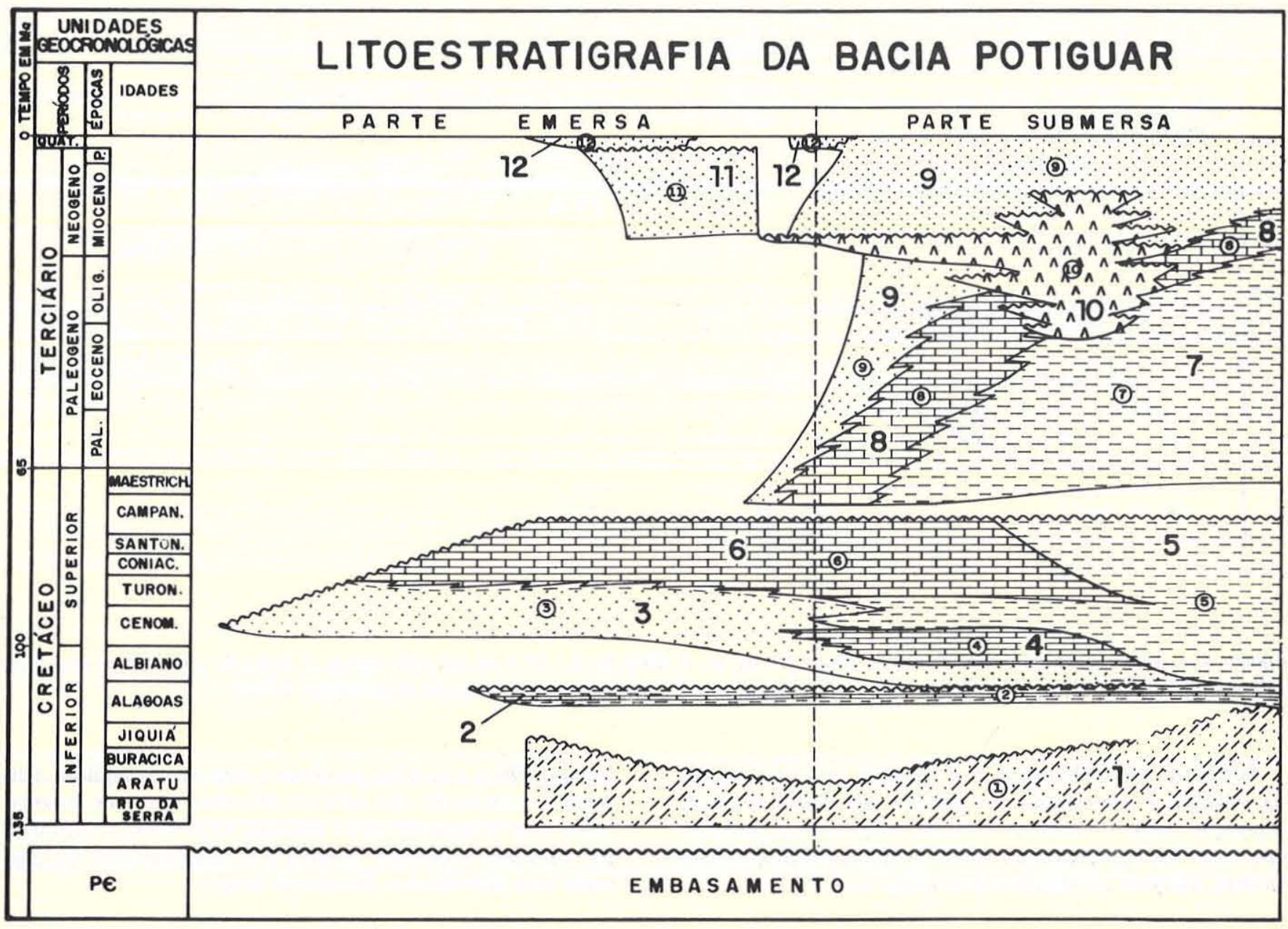

Figura 3 - Quadro litoestratigráfico da Bacia Potiguar: 1. Formação Pendência; 2. Formação Alagamar; 3. Formação Açu; 4. Formação Ponta do Mel; 5. Formação Ubarana, Membro Quebradas; 6. Formação Jandaíra; 7. Formação Ubarana; 8. Formação Guamaré; 9. Formação Tibaú; 10. Formação Macau; 11. Formação Barreiras; 12. Sedimentos recentes. Modificado de Souza (1982) pelo grupo de trabalho Petrobrás/Debar/Dinter em 1984

ção submersa, cujo limite sul é marcado por falhas NW-SE, subparalelas à atual linha de costa. Seus limites leste e oeste são os altos de Touros e de Fortaleza, respectivamente (Fig. 5). Na parte emersa da bacia, os grábens são de direção NE-SW e limitados a leste pela Plataforma Leste e a oeste pela Plataforma de Baraúnas (Fig. 5).

Internamente ao gráben da área emersa, são encontrados vários altos do embasamento, os quais podem ser assim agrupados: um conjunto alinhado na direção NE-SW localizado no eixo central do gráben e denominado Alto de Quixaba; e, fora desse alinhamento, nas proximidades da linha de costa, um grande alto interno, de forma aproximadamente triangular com a base voltada para norte, denominado Alto de Macau (Fig. 5).

No início do segundo ciclo tectono-sedimentar, grande parte desses altos internos permanecia sem cobertura sedimentar (Fig. 6). No início do terceiro ciclo, apenas pequenas porções dos altos permaneciam sem cobertura (Fig. 7) e, finalmente, durante o terceiro ciclo foram totalmente cobertos (Fig. 8).

As plataformas Leste e Baraúnas são de paleorrelevo suave a aplainado, e circundam os grábens da parte submersa e da emersa da bacia. No início do segundo ciclo tectono-sedimentar, essas plataformas permaneciam aflorantes, pois a cunha sedimentar limitava-se aos grábens (Fig. 6). Durante o segundo ciclo as áreas próximas aos grábens foram cobertas por sedimentos da Formação Alagamar, os quais foram removidos em parte pela erosão ocorrida no final do ciclo (Fig. 7). Os limites dos sedimentos remanescentes ultrapassam e são paralelos aos limites de deposição da fase anterior (Figs. 6 e 7). Durante o terceiro ciclo, essas plataformas são totalmente cobertas por sedimentos da Formação Açu, que são progradantes, a partir do gráben em direção às plataformas, principalmente no sentido de oeste para leste. Como resultado, os sedimentos da Formação Açu em contato com o embasamento na parte ocidental da Plataforma Leste são mais antigos que aqueles em contato com o embasamento na parte oriental da mesma. 


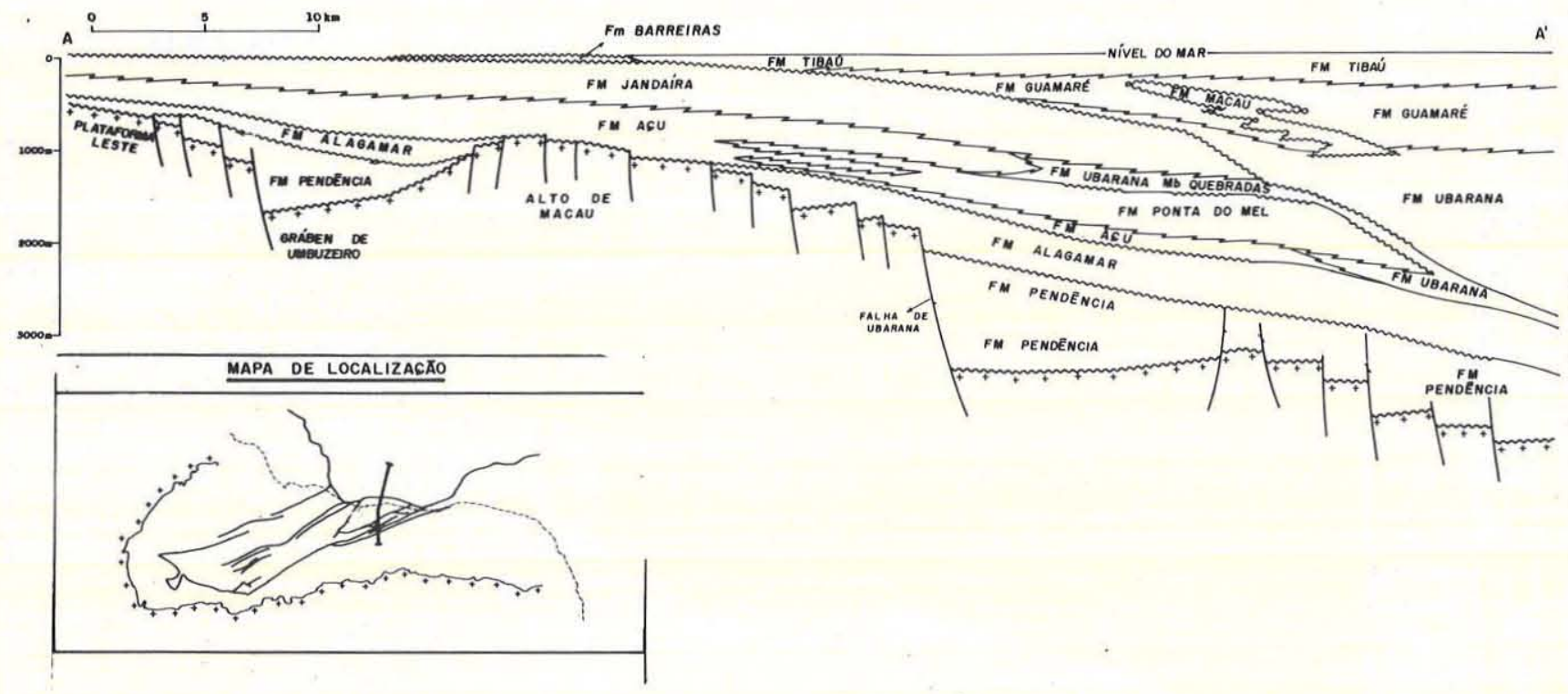

Figura 4 - Seção geológica estrutural da Bacia Potiguar. A direção A-A' é de sul para norte. A linha de costa atual está locacalizada próxima ao contato entre as formações Barreiras e Tibaú (segundo Françolin \& Szatmari 1985)

Portanto, resumidamente, o arcabouço estrutural da Bacia Potiguar é constituído por grábens que foram sítios de deposição desde o Cretáceo Inferior, ladeados por plataformas rasas do embasamento sobre os quais a sedimentação ocorreu somente no Mesocretáceo (Figs. 5, 6, 7 e 8).

BACIA DO RIO DO PEIXE Estratigrafia A Bacia do Rio do Peixe está preenchida por sedimentos terrígenos continentais de idade neocretácea (Braun 1969, apud Radambrasil op. cit). Esses sedimentos foram divididos por Braun em três unidades, posteriormente denominadas por Albuquerque (1970) formações Antenor Navarro, Souza e Rio Piranhas (Radambrasil op. cit.). Essas formações fazem parte de um único ciclo tectono-sedimentar e são correlacionáveis em idade e ambiente tectono-sedimentar à Formação Pendência da Bacia Potiguar.

FORMAÇÃO ANTENOR NAVARRO É constituída de conglomerados e arenitos fluviais imaturos na base, passando gradativamente para arenitos finos e micáceos intercalados com argilitos no topo. Está depositada discordantemente sobre o embasamento cristalino e aflora principalmente na porção norte da Bacia do Rio do Peixe. Representa a porção basal da seqüência, foi depositada sob forte influência tectônica e freqüentemente é encontrada falhada e brechada.

FORMAÇÃO SOUZA , É constituída por argilitos intercalados a níveis de margas e arenitos finos, com abundantes níveis fossilíferos e pegadas de dinossauros. Seus contatos inferior e superior são concordantes e gradacionais com as formações Antenor Navarro e Rio Piranhas, respectivamente. Foi depositada em ambiente subaquoso e tectonicamente calmo.

FORMAÇÃO RIO PIRANHAS Teve sua deposição por arenitos finos a médios, micáceos e com matriz argilosa. Seu topo é constituído por arenitos grossos e imaturos, intercalados com conglomerados e brechas. Representa a retomada da atividade tectônica na área e o assoreamento do lago onde fora depositada a Formação Souza.

Arcabouço Estrutural A Bacia do Rio do Peixe é constituída por dois meio-grábens assimétricos, ambos com mergulho para sul, separados por um alto interno de direção NE-SW (Fig. 9).

No levantamento gravimétrico efetuado por Rand (1984) são claramente divisíveis as duas sub-bacias e o alto interno que as separa. Denomina-se aqui esse alto interno de Santa Helena, por estar a localidade homônima situada nas proximidades de seu limite SW. O limite sudeste do Alto de Santa Helena é dado pela Falha de Portalegre de direção NE-SW, enquanto o limite norte é marcado por uma falha de direção ENE, que nas proximidades da localidade de Brejo das Freiras se bifurca da Falha de Portalegre e corta toda a seqüência sedimentar até o limite oeste da bacia (Fig. 9).

Rand (1984) denominou o gráben a nordeste do Alto de Santa Helena de sub-bacia NW e o gráben a sudeste do mesmo alto de sub-bacia SE. A sub-bacia NW abriga as formações Antenor Navarro e Souza. A primeira aflora na maior parte de sua extensão areal enquanto a segunda cobre pequena área, contornando o Alto de Santa Helena (Fig. 9). O limite SE dessa sub-bacia é dado pela Falha de Portalegre. Durante os trabalhos do campo, foram visitados afloramentos localizados sobre a Falha de Portalegre, tanto na área onde ela limita a bacia quanto a área que ela corta os sedimentos e limita o Alto de Santa Helena. Nessas oportunidades, foram constatadas fortes evidências da movimentação lateral dextral dessa falha. Nas áreas onde a falha limita a bacia são encontradas brechas tectônicas constituídas por 


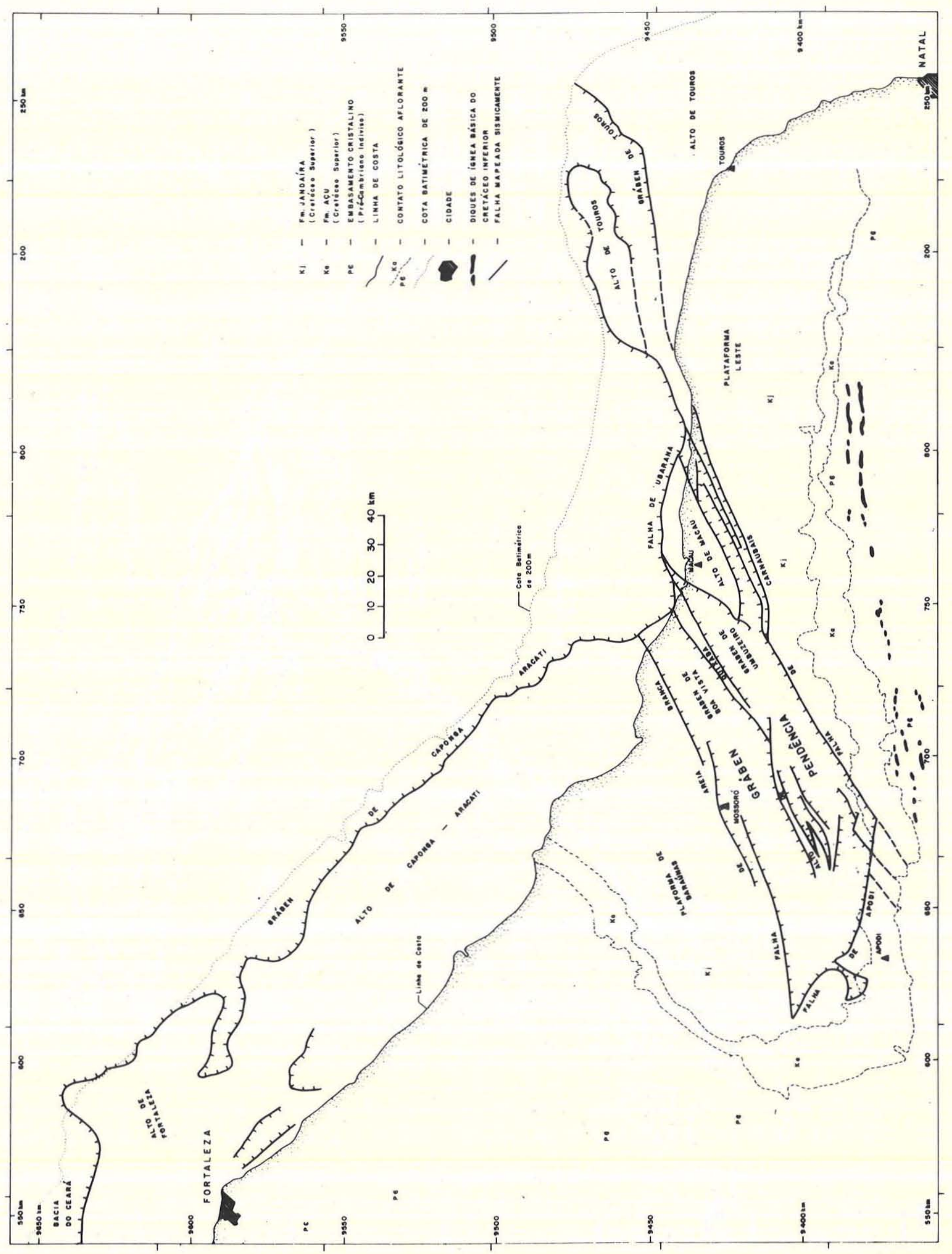

Figura 5 - Arcabouço estrutural e limites dos grábens da Bacia Potiguar. Integrado de diversos mapas da Petrobrás/Debar e Dirnoe (segundo Françolin \& Szatmari 1985) 


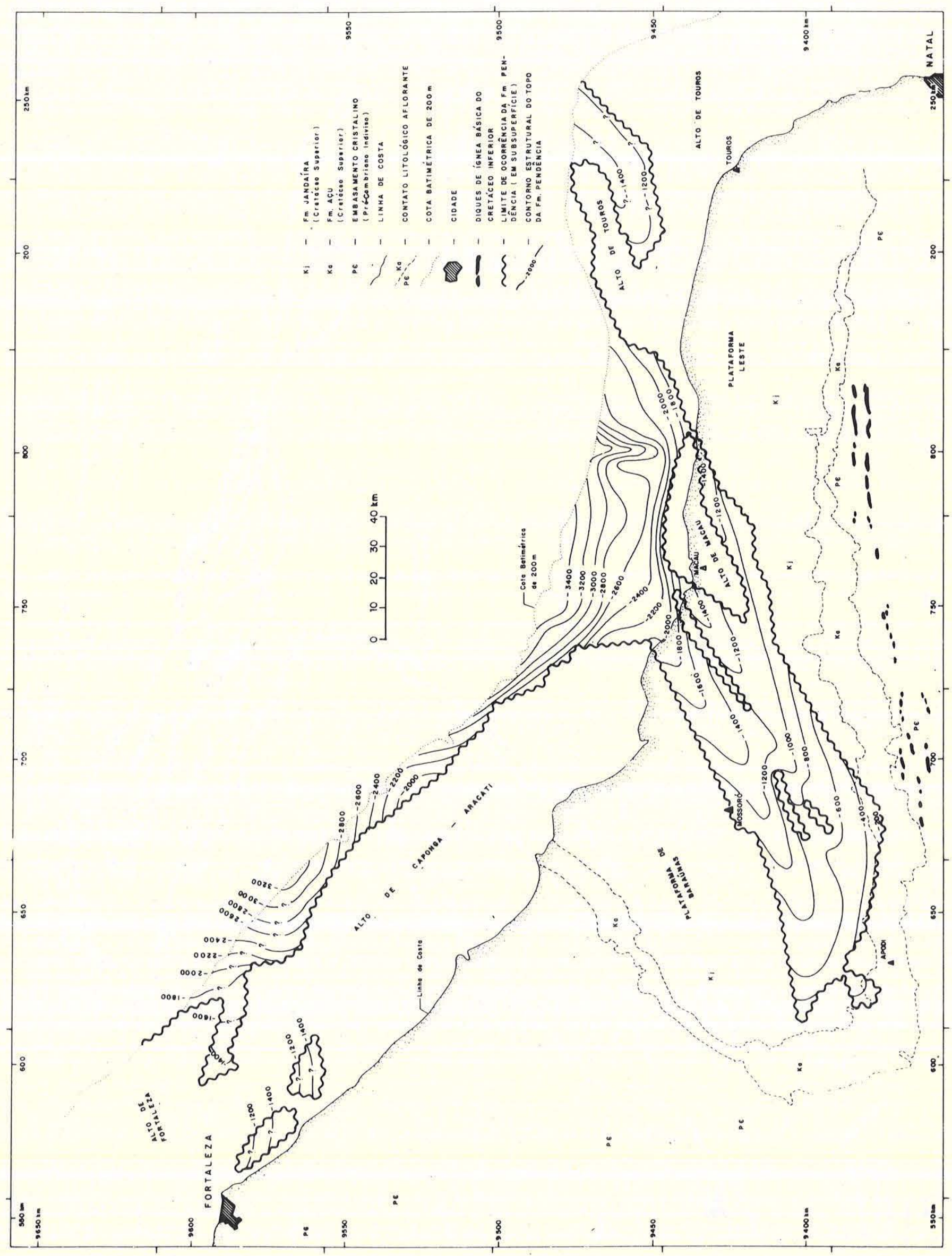

Figura 6 - Mapa estrutural do topo da Formação Pendências (estrutural da discordância pré-Aptiana). Modificado de Projeto Alagamar (inédito) (segundo Françolin \& Szatmari 1985) 


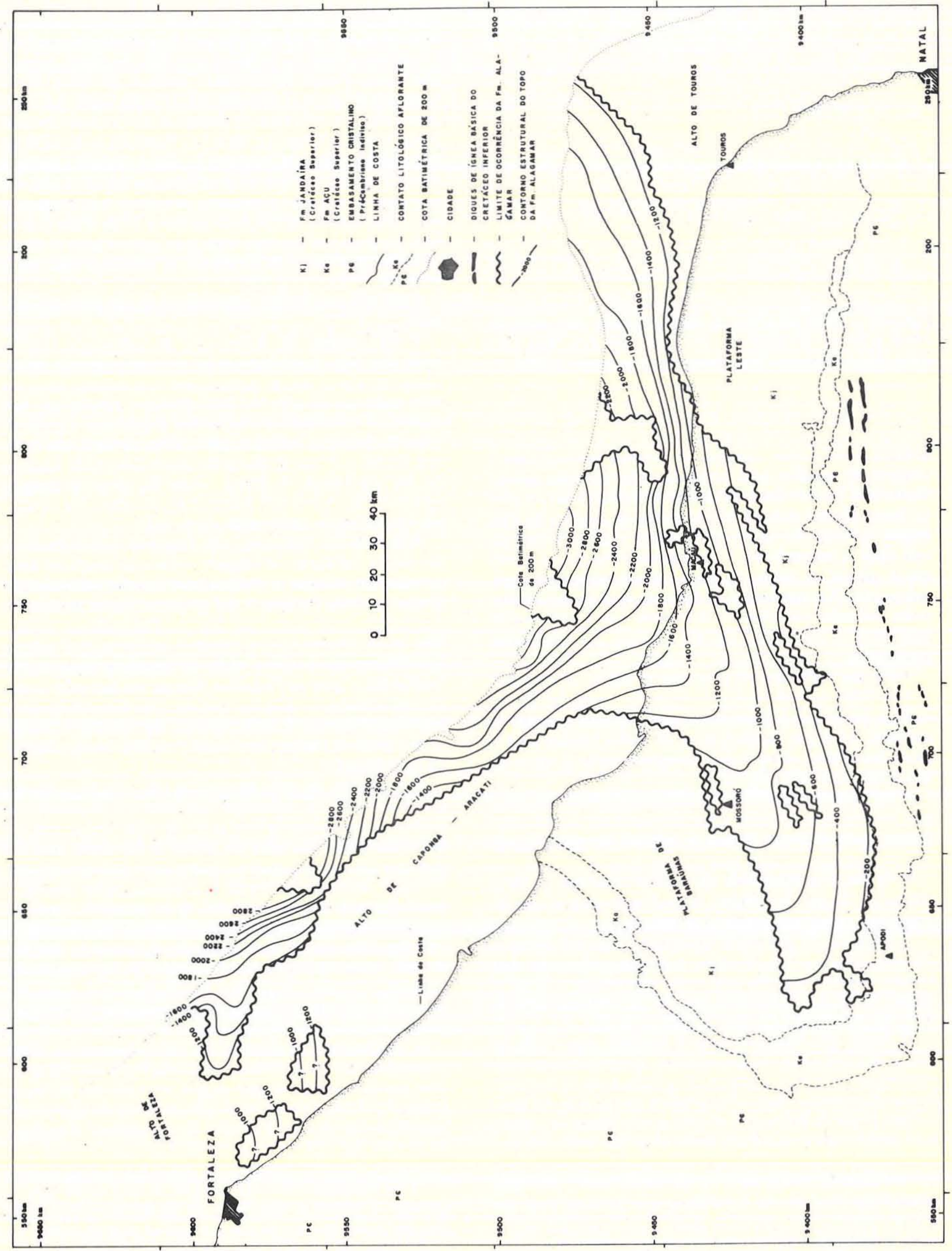

Figura 7 - Mapa estrutural do topo da Formação Alagamar (estrutural da discordância pré-Albiana). Modificado de Projeto Alagamar (inédito) (segundo Françolin \& Szatmari 1985) 


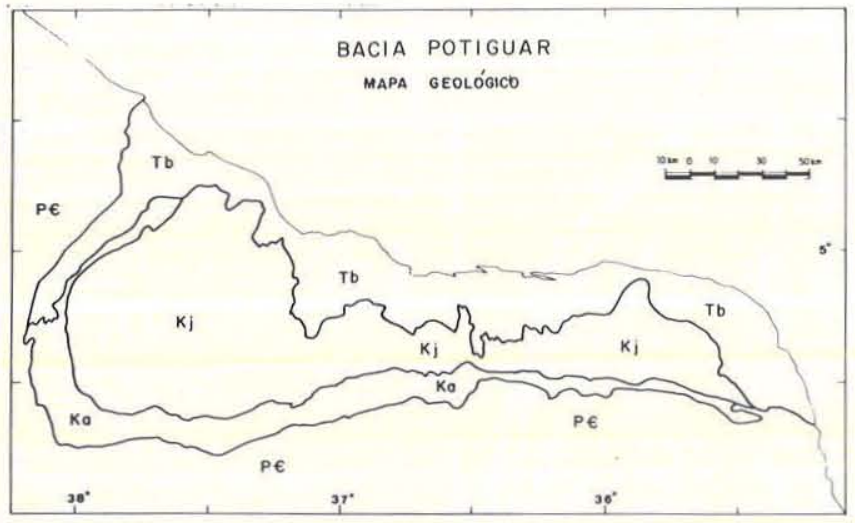

Figura 8 - Mapa geológico da Bacia Potiguar, mostrando as atuais áreas de afloramento das formações Açu (Ka), Jandaira (Kj) e Barreiras (Tb): Françolin \& Szatmari (1985)

arenitos e milonitos, camadas de arenitos verticalizadas e camadas de arenitos com planos de falha estriados subverticalmente. $\mathrm{Na}$ área onde a Falha de Portalegre limita o Alto de Santa Helena existem afloramentos de arenitos da Formação Antenor Navarro extremamente cisalhados com locais onde o acamamento é totalmente obliterado por inúmeros planos de falha, os quais exibem estriamento sub-horizontal. Nas imediações da falha, as camadas de arenitos estão dobradas suavemente, indicando que a deformação antecedem o endurecimento dos arenitos por cimentação diagenética.

Além das evidências de afloramento têm-se as regionais:

- A Falha de Portalegre, a nordeste do Açude dos Pilões, limita a bacia com o bloco baixo para noroeste enquanto a sudoeste do açude limita o Alto de Santa Helena com o bloco baixo para sudeste. Este comportamento é típico de falhas transcorrentes (Fig. 9).

- As camadas das duas sub-bacias mergulham em geral para sul, variando poucos graus para sudeste ou sudoeste. Sobre o Alto de Santa Helena as camadas mergulham para $\mathrm{NE}$, em discrepância com todo o resto da bacia.

- O mapa gravimétrico da área mostra que as duas sub-bacias foram deslocadas dextralmente pela Falha de Portalegre, conforme sugere Rand (1984).

A sub-bacia SE está preenchida pelas formações Antenor Navarro, Souza e Rio Piranhas. A primeira aflora em suas porções norte; a segunda domina os afloramentos da parte central e sul; a terceira flora apenas em pequena área da parte sul, margeando a Falha de Malta (Fig. 9).

O limite sul dessa sub-bacia é marcado pela Falha de Malta, que faz parte da grande zona de cisalhamento pré-cambriano de Patos. Durante os trabalhos de campo não foram encontrados bons afloramentos de sedimentos limítrofes à Falha de Malta, pois aí ocorre uma freqüente cobertura quaternária e os acessos rodoviários são mais exíguos. Entretanto, afloramentos examinados pelos autores a leste da sub-bacia ao longo da zona de cisalhamento de Patos apresentam critérios de movimento que indicam uma pequena reativação transcorrente sinistral presumivelmente durante a deposição dos sedimentos que preencheram a bacia.

EVOLUÇÃo TECTONO-SEDIMENTAR A idade dos sedimentos da Fase Rifte das bacias cretáceas brasileiras é coerente com a proposição de que, no período compreendido entre o final do Jurássico e o final da Idade Alagoas (Aptiano), o rifte da separação América do Sul e África propagou-se desde o extremo sul da atual costa leste sul-americana até o Gráben de Cassiporé no extremo oeste da costa brasileira (Figs. 1a, 1b e 1c). Szatmari et al. (1985a) propuseram que esta propagação tenha ocorrido graças à rotação horária da Placa sul-americana em relação à africana ao redor de um pólo localizado, durante o Neocomiano, a aproximadamente $390 \mathrm{~W}$ de longitude e 70 de latitude (Fig. 1b). No início da Aptiano, esse pólo migrou para as proximidades do Gráben de Cassiporé, aí permanecendo até o início do Albiano (Fig. 1c).

Essas proposições são sustentadas por três pontos principais:

- Os estudos de Rabinowitz \& LaBrecque (1979), realizados com dados levantados principalmente no sul do Atlântico Sul e bacias sedimentares adjacentes, tanto do lado argentino quanto do lado africano, concluíram, por datação e correlação de anomalias magnéticas e gravimétricas do assoalho oceânico, que o início da separação América do Sul e África se deu pela rotação horária da América do Sul em relação à África, o que fez parte da margem equatorial Sul-Americana permanecer, durante o Neocomiano, sob regime de compressão norte-sul.

- As datações realizadas pela Petrobrás nos sedimentos das bacias cretáceas da margem equatorial brasileira comprovam que durante o Neocomiano ocorreu sedimentação apenas na Bacia Potiguar e nas pequenas bacias internas do continente, entre elas a do Rio do Peixe (Braun 1969). Não foram encontrados sedimentos cretáceos mais antigos que Alagoas nas bacias a oeste de Eortaleza. Essas bacias, localizadas a oeste de Fortaleza, tiveram sua fase rifte iniciada tardiamente no Alagoas Inferior. Tal fato comprova a tese de Rabinowitz \& LaBrecque de que durante o Neocomiano parte da margem equatorial brasileira esteve submetida a compressão.

- A posição do pólo neocomiano de rotação, proposto por Rabinowitz \& LaBrecque nas cercanias do ponto hoje ocupado pela cidade de São Luís, foi aqui considerada sobre o meridiano que passa na cidade de Fortaleza, uma vez que este neocomiano marca o limite oeste da sedimentação.

Como resultado da rotação neocomiana acima descrita, a área localizada nas proximidades da interseção da costa leste e da costa equatorial ficou submetida a um sistema de esforços diferente de toda a margem atlântica da América do Sul. Nessa época, graças à rotação, a área atualmente ocupada pelas bacias Potiguar e Rio do Peixe e suas adjacências sofria um esforço de distensão de direção $\mathrm{N}-\mathrm{S}$ e compressão de direção E-W (Fig. 1b).

A distribuição de critérios de cisalhamento das falhas eocretáceas das bacias Potiguar e Rio do Peixe são coerentes com sua formação sob esse regime de esforços. Na Bacia Potiguar, os abatimentos se deram devido à movimentação transtencional dextral da Falha de Carnaubais-Portalegre de direção NE-SW e outras subparalelas que ocorrem delimitando o Alto de Quixaba. As falhas normais de direção E-W ou levemente NW-SE completavam o arcabouço, limitando o gráben a sul (Falha de Apodi) ou influindo na posição da atual linha de costa (Falha de Ubarana) (Fig. 5).

As falhas de Apodi e Carnaubais-Portalegre se interceptam em um ponto alinhado aos diques do Magmatismo Rio Ceará-Mirim, citados na introdução deste trabalho, os quais 


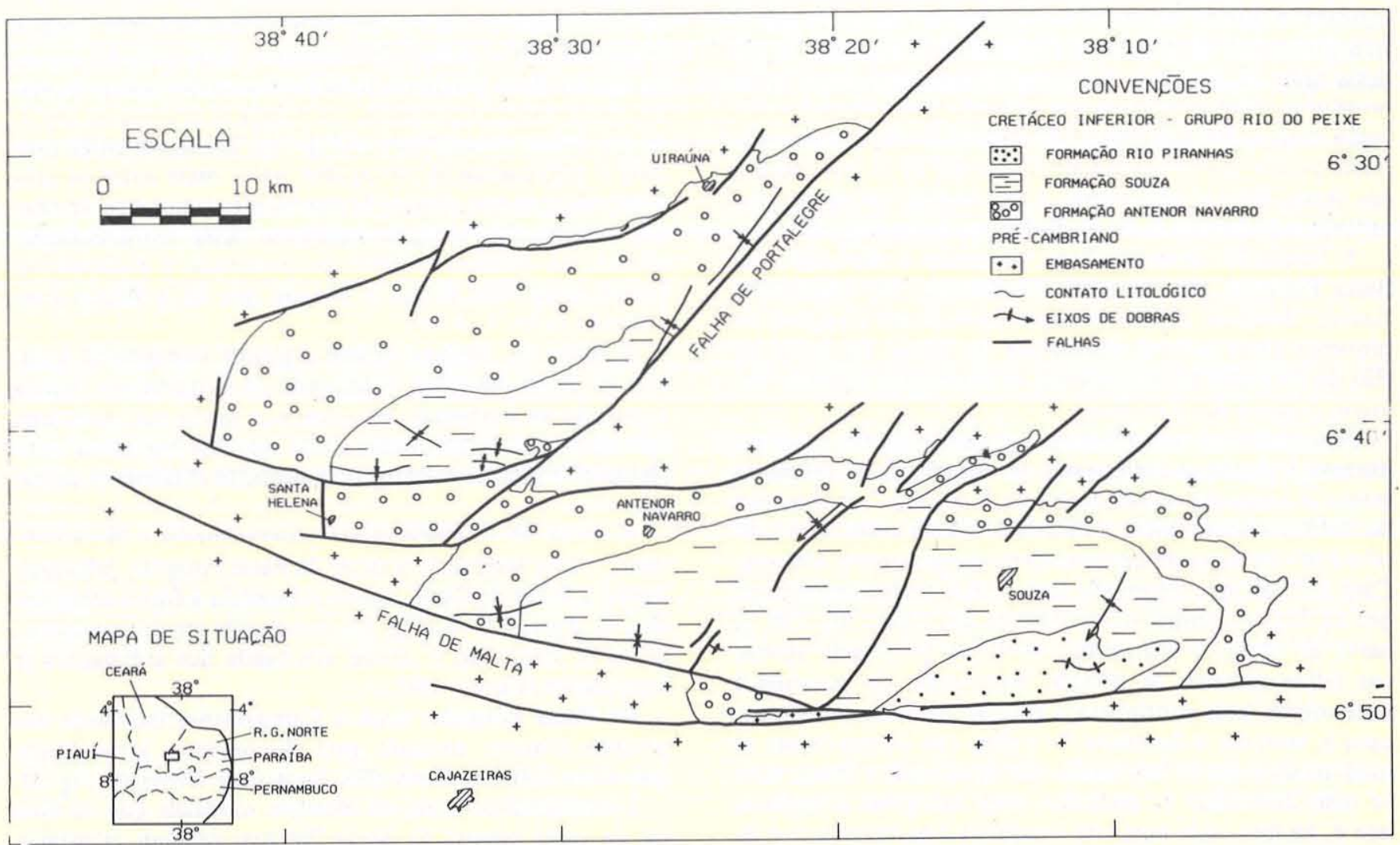

Figura 9 - Mapa geológico da Bacia do Rio do Peixe ressaltando as principais feiçóes estruturais. Modificado de DNPM (1969) por Françolin \& Szatmari (1985)

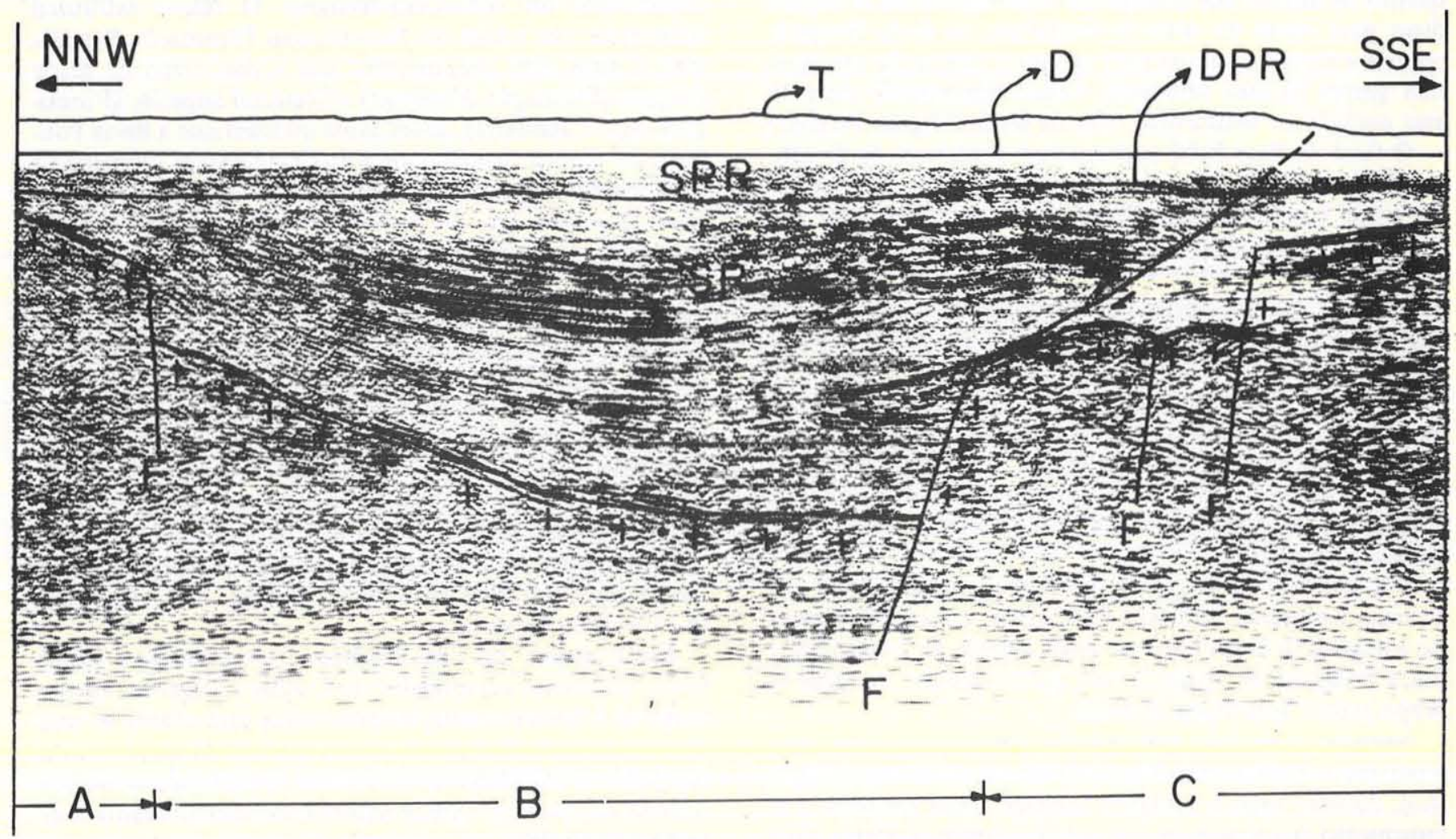

Figura 10 - Linha sismica da Bacia Potiguar. Notar o dobramento das camadas, causado pela falha reversa. A. Alto de Quixabá; B. Gráben de Umbuzeiro; C. zona afetada pela Falha de Carnaubais; T. topografia do terreno; D. Datum (nivel do mar); DPR. discordância pós-rifte (pré-Aptiano); SR. Seqüência Rifte; SPR. Seqüência pós-Rifte; F. falha (interpretado por Françolin \& Szatmari 1985) 
marcam o limite entre a movimentação transtensional e transpressional da Falha de Carnaubais-Portalegre. A sul dessa linha de diques o comportamento dessa falha é transpressional, com exceção de seu extremo SW, onde sua interseção com a faixa de Patos, de direção E-W, é complexa. Neste ponto, a movimentação diferencial de blocos causava em alguns limites compressão e, em outros, distensão, permitindo a formação da Bacia do Rio do Peixe (Fig. 2).

A formação desses grábens propiciou a deposição, na Bacia Potiguar, da Formação Pendências com sedimentos fluviais, deltáicos e lacustres, que representam o registro do primeiro ciclo tectono-sedimentar da bacia. Na Bacia do Rio do Peixe foram depositadas as formações Antenor Navarro, Souza e Rio Piranhas.

Esse ciclo foi interrompido, na parte emersa, quando, durante o Jiquiá, a compressão de direção $\mathrm{E}-\mathrm{W}$ terminou graças à completa acomodação do "cotovelo" da América. do Sul (interseção entre o rifte NE-SW da costa leste è do rifte NW-SE da costa equatorial) na margem oeste africana. Com o final da compressão leste-oeste foram interrompidos os deslocamentos transcorrentes das falhas NE-SW. A partir de então, o abatimento de blocos prosseguiu apenas nas falhas normais de direção leste-oeste ou próxima à leste-oeste, pois continuava a rotação da Placa Sul-Americana e, com ela, a distensão N-S (Fig. 1c). Dessas falhas, as mais ativas eram as localizadas nas áreas onde a crosta estava mais distendida e, portanto, mais suscetível à ruptura, isto é, na área onde hoje está localizada a parte submersa da Bacia Potiguar. Nessa área prosseguịu o rifteamento e a deposição enquanto na área emersa, onde a movimentação transtensional era preponderante no ciclo anterior, instalou-se um período erosivo. Durante o Eoalagoas, enquanto os limites dos grábens da costa equatorial se expandiam para oeste do Alto de Fortaleza, na Bacia Potiguar ocorria a erosão na atual área emersa e deposição em algumas partes da área submersa. Foram depositados durante esse período os sedimentos rifte da idade Alagoas Inferior.

$\mathrm{O}$ final da Fase Rifte ocorreu com a interrupção da subsidência acentuada, mas restrita, e o início de uma subsidência lenta e generalizada. Ocorreu, então, a deposição dos sedimentos da Formação Alagamar em ambiente tectônico progressivamente mais tranqüilo. A diminuição da taxa de subsidência causou o progressivo entulhamento da bacia e a deposição desses sedimentos sobre o gráben da atual parte emersa e sobre as bordas das plataformas Leste e de Baraúnas (Fig. 7). A qualidade da matéria orgânica e a presença de dinoflagelados nos folhelhos dessa fase (Alagoas Superior) indicam uma possível influência marinha na sedimentação (Rodrigues et al. 1983). Os sedimentos da Formação Alagamar representam o segundo ciclo tectono-sedimentar da Bacia Potiguar.

Durante a Idade Alagoas, o rifte avançou para oeste até alcançar o extremo ocidental da margem equatorial e permitiu a deposição de sedimentos desde a Bacia do Amapá até a Bacia Potiguar, ao longo de um grande gráben alongado e subparalelo à atual linha de costa.

Segundo o modelo apresentado, permanecia ainda sem separação o trecho entre Touros (RN) e João Pessoa (PB), o qual, durante todo o Cretáceo Inferior, havia deslizado em movimento transcorrente compressivo contra a África. Portanto, no início do Albiano, os continentes sul-americano e africano tinham entre si um longo e estreito rifte desde a Argentina até o gráben de Cassiporé, interrompido apenas no trecho entre Touros e João Pessoa, onde, apesar de não ter ainda ocorrido distensão, a crosta já se encontrava cortada por falhas transcorrentes (Fig. 1c). Tornou-se então possível a movimentação divergente leste-oeste entre os dois atuais continentes, através de movimento transcorrente dextral ao longo da margem equatorial. Essa movimentação, iniciada no Albiano Inferior, proporcionou a distensão no trecho entre João Pessoa e Touros, que foi o último a ser separado (Figs. 1c e 1d).

A partir do Albiano ocorre a grande transgressão marinha na Bacia Potiguar, culminada no Campaniano com a deposição da Formação Jandaíra, e, a partir daí, após uma fase de erosão generalizada, a fase marinha regressiva completou a seqüência estratigráfica presente atualmente na bacia.

A partir do Coniaciano até provavelmente o Maestrichtiano, a área localizada a oeste da Bacia Potiguar, principalmente a Bacia do Ceará, esteve submetida a fortes compressões de direção N-S (Fig. 1e), resultando em dobramentos, falhas de empurrão e erosão acentuada dos sedimentos já depositados (Gorini 1981).

$\mathrm{Na}$ Bacia Potiguar, após o Campaniano, iniciou-se um período erosivo, atestado pela discordância generalizada que atuou sobre as formações Jandaíra e Ubarana (Fig. 3).

Levantamentos sísmicos recentes mostram que na área sul da parte emersa da Bacia Potiguar existem estruturas compressionais como falhas reversas e dobras (Fig. 10). Apesar da baixa resolução sísmica nos horizontes mais rasos (formações Açu e Jandaíra), em algumas das linhas é evidente a perturbação causada por essas estruturas nos níveis depositados no Albo-Cenomaniano. O relevo estrutural observado nos níveis do Neocomiano (Formação Pendências) é bem mais pronunciado que o dos níveis de Idade Alagoas (Formação Alagamar) e Cretáceo Superior (Formações Açu e Jandaíra). Esses fatos indicam que a Bacia Potiguar, da mesma maneira que a do Ceará, esteve submetida a uma forte compressão de direção norte-sul durante o Cretáceo Superior que, ou gerou essas estruturas, ou reativou estruturas preexistentes. Na primeira hipótese a diferença de relevo estrutural entre os sedimentos neocomianos (Formação Pendências) e os sobrepostos pode ser atribuída ao fato de estarem os primeiros confinados ao gráben e os últimos depositados sobre uma ampla superfície relativamente plana, e, portanto, com maior possibilidade de deslocamentos horizontais. Na segunda hipótese, o relevo estrutural mais pronunciado na Formação Pendências seria o resultado da somatória de dois eventos compressionais: o primeiro ocorrido entre o Jiquiá e o Alagoas, de natureza e direção pouco conhecidas; e o segundo de direção norte-sul e correlacionável ao ocorrido na Bacia do Ceará durante o Cretáceo Superior.

Em qualquer das duas hipóteses fica evidente a importância do evento compressivo do Cretáceo Superior, aparentemente o último evento deformacional importante da margem equatorial. Destaca-se sua capacidade de gerar estruturas novas e modificar as anteriores, ressaltando-as ou destruindo-as, em uma época anterior ou concomitante à geração de petróleo. 


\section{REFERÊNCIAS BIBLIOGRÁFICAS}

ALBUQUERQUE, J.P.T. - 1970 - Inventário hidrogeológico básico do Nordeste, Folha 15 Jaguaribe, CE, Recife, Sudene (Série Hidrogeológica 32$), 18 \mathrm{p}$.

ALMEIDA, F.M. \& HASUI, Y. (coords.) - 1984 -O Pré-Cambriano do Brasil. São Paulo, Blücher. 378 p.

ASMUS, E.H. \& GUAZELLI, W. - 1981 - Descrição sumária das estruturas da margem continental brasileira e das áreas oceânicas e continentais adjacentes. In: Petrobrás. Estruturas e tectonismo da margem continental brasileira, e suas implicą̧ōes nos processos sedimentares e na avaliação do potencial de recursos minerais. Rio de Janeiro. Cenpes/Dintep. p. 187-269. (Série Projeto Remac 9).

BRAUN, O.P.G. - 1969 - Geologia da Bacia do Rio do Peixe nordeste do Brasil. Rio de Janeiro, Prospec/DNPM. 23 p.

EBERT, H. \& BROCHINI, M.F. - 1968 - Estudos estratigráficos e geocronológicos no Escudo Cristalino Brasileiro. Ci. Cult., 20(3):621-625.

FRANCCOLIN, J.B.L. \& SZATMARI, P. - 1985 - Mecanismo de to da porção oriental da margem norte brasileira. In: CONGR. BRAS. PALEONT., 9, Fortaleza, 1985. (Apres. ord).

GORINI, M.A. - 1981 - The tectonic fabric of the Equatorial Atlantic and adjoining continental margins. Gulf of Guinee to northeastern Brazil. In: Petrobrás. Estruturas e tectonismo da margem continental brasileira, e suas implicações nos processos sedimentares e na avaliação do potencial de recursos minerais. Rio de Janeiro. Cenpes/Dintep. p. 11-116. (Série Projeto Remac 9).

PROJETO RADAMBRASIL - 1981 - Ministério das Minas e Energia, v. 23, p. 133-136.

RABINOWITZ, P.D. \& LaBRECQUE, V. - 1979 - The Mesozoic South Atlantic Ocean and evolution of its continental margin. J. Geophys. Res., 84(B11):5973-6002.

RAND, H.M. - 1984 - Reconhecimento gravimétrico da Bacia do Rio do Peixe, Paraíba. In: SIMP. GEOL. NORDESTE, 11, Natal 1984. Anais... Natal. SBG. Núcleo NE. p. $42-47$.
REGALI, M.S.P. \& GONZAGA, S.M. - 1982 - Palinocronoestratigrafia da Bacia Potiguar. Rio de Janeiro, Petrobrás/Cenpes (Relatório interno).

RODRIGUES, R.; FRANÇOLIN, J.B.L.; LIMA, H.P. - 1983 Avaliação geoquímica preliminar da Bacia Potiguar Terrestre. Rio de Janeiro, Petrobrás/Cenpes/Depex. (Relatório interno).

SIAL, A.N. - 1976 - The Rio Grande do Norte alkali-olivine basalt association, Northeast Brazil. Rev. Bras. Geoc., 6(1):1-14. 6(1):1-14.

SOUZA, S.M. - 1982 - Atualização da litoestratigrafia da Bacia Potiguar. In: CONGR. BRAS. GEOL., 32, Salvador 1982. Anais... Salvador, SBG. v. 5, p. 2392-2406.

SZATMARI, P.; CONCEIÇÃO, J.C.L.; LANA, M.S.; MILANI, E.J.; LOBO, A.P. - 1984 - Mecanismo tectônico do rifteamento sul-atlântico, In: CONGR. BRAS. GEOL., 33, Rio de Janeiro 1984. Anais... Rio de Janeiro, SBG. v. 4, p. 1529-1601.

SZATMARI, P.; ZANOTTO, O.; FRANÇOLIN, J.; WOLFF, S. 1985a - Rifting and early tectonic evolution of the Equatorial Atlantic. In: GEOL. SOC. AMERICA 98th ANNUAL MEETING, Orlando, Flórida, 1985. Abstracts with programs... p. 731.

SZATMARI, P.; FRANÇOLIN, J.; ZANOTTO, O. WOLFF, S. 1985b - Rifteamento na Margem Equatorial do Brasil. In CONGR. BRAS. PALEONT., 9, Fortaleza, Bol. Res... Rio de Janeiro, Soc. Bras. Paleont. p. 91.

SZATMARI, P.; FRANÇOLIN, J.B.L.; ZANOTTO, O.; WOLFF, S. - 1987 - Evolução tectônica da margem equatorial brasileira. Rev. Bras. Geoc., 17(2):180-188.

MANUSCRITO 403

Recebido em 30 de outubro de 1986 Revisão aceita em 28 de abril de 1986

... Ê uma ilusão comum acreditarmos que o que sabemos hoje é tudo o que poderemos saber para sempre. Nada é mais vulnerável que uma teoria científica, apenas uma tentativa efêmera para explicar fatos e nunca uma verdade eterna. 